\title{
Correlates of Permanent Tooth Development in Prenatal Time
}

\author{
ALPHONSE R, BURDI, STANLEY M. GARN, and JERRY SUPERSTINE \\ Department of Anatomy and Center for Human Growth, University of \\ Michigan, Ann Arbor, Michigan 48104, USA
}

Although calcification of the permanent teeth is not radiologically discernible until the first month after birth (GARN, LEwIS, and POLACHECK, $J$ Dent Res 38: 135, 1959) developmental stages of $11,12, M 1$, and often $\mathrm{C}$ may be demonstrated in histological sections of jaws well before the 39. to 4l-week age horizon. It is of interest, therefore, to determine whether intra-uterine development of these permanent teeth is simply and linearly related to the conventional measures of fetal size, namely, crown-rump length (CRL) and weight. It is also interesting to ascertain whether the correlation between fetal size and the overall measure of permanent tooth development obtained by summing individual tooth stages is sufficient to make dental development a reference parameter in prenatal studies.

To do this, we have related the stage of development of $I 1,12$, and $M l$ in the maxilla and mandible separately to (I) crown-rump length, (2) weight, and (3) the base-10 logarithm of body weight in 34 grossly and histologically nor. mal human fetuses. We have used a simple system of "staging" as previously described by us (GARN and Burdr, $J$ Dent Res 50: 1407, 1971; Burdi, Garn, and Babler, Arch Oral Biol 19: in press, 1974). Data on permanent canines were excluded because the small number of fetuses providing definitive developmental information was insufficient to compute valid correlations involving $\mathrm{C}$. Linearity of relationship,

This research was supported by Grant DE 03443 from the National Institute of Dental Health and by the Beatrice Stanton Medical Research Fund of the University of Michigan.

Received for publication July 29, 1974.

Accepted for publication October 16, 1974. after pooling separate sex-specific values of $r$, was tested before computing final productmoment correlations $(\boldsymbol{r})$.

As shown in the table, correlations between the stage of development of three maxillary and three mandibular teeth and the measures of fetal size were moderate to high. Individual tooth-stage vs body-size correlations ranged from 0.691 to 0.933 with a weighted mean value of $r$ approximating 0.85 . Throughout, correlations involving maxillary teeth were higher than those involving corresponding mandibular teeth, a trend that was statistically significant by chisquare test.

With the summed tooth measure $(\Sigma T)$ correlations involving length, weight, and the base10 logarithm of weight were consistently higher than correlations involving single teeth. Correlations between summed tooth stage of 11,12 , and Ml and CRL, body weight, and $\log _{10}$ body weight ranged from 0.867 to 0.972 . The highest correlation (0.972) was between summed maxillary tooth stage and CRL.

While it is not surprising that permanent tooth development and size are significantly correlated in human fetuses between 75 and 378 $\mathrm{mm}$ in CRL, both the linearity of the relationships and the magnitudes of the correlations should be noted. Since correlations involving $\Sigma T$ and fetal size range up to $0.972, \Sigma T$ may provide a useful measure of "dental age" in fetal studies, appropriate as a reference standard in the analysis of prenatal craniofacial development. Finally, dental development may provide a useful, independent reference parameter in embryological research.

We appreciate access to fetal material generously provided by Dr. James K. Avery.

Permanent Tooth Development and Fetal Size

\begin{tabular}{|c|c|c|c|c|c|c|c|}
\hline \multirow[b]{2}{*}{ Tooth } & \multirow{2}{*}{$\begin{array}{l}\text { Crown-Rump } \\
\text { Length }\end{array}$} & \multicolumn{2}{|c|}{$\begin{array}{l}\text { Crown-Rump } \\
\text { Length }\end{array}$} & \multicolumn{2}{|c|}{ Body-Weight } & \multicolumn{2}{|c|}{ Log Body-Weight } \\
\hline & & $\mathbf{N}$ & $\boldsymbol{T}$ & $\mathbf{N}$ & $\boldsymbol{r}$ & $\mathbf{N}$ & $T$ \\
\hline $\begin{array}{l}\text { Maxillary } \\
\text { I1 } \\
\text { I2 } \\
\text { MI } \\
\text { Summed }\end{array}$ & $\begin{array}{r}110-378 \\
170-350 \\
75-350 \\
75-343\end{array}$ & $\begin{array}{l}24 \\
18 \\
22 \\
20\end{array}$ & $\begin{array}{l}0.890 \\
0.890 \\
0.915 \\
0.972\end{array}$ & $\begin{array}{l}26 \\
18 \\
21 \\
18\end{array}$ & $\begin{array}{l}0.854 \\
0.930 \\
0.786 \\
0.910\end{array}$ & $\begin{array}{l}26 \\
18 \\
21 \\
18\end{array}$ & $\begin{array}{l}0.782 \\
0.900 \\
0.933 \\
0.939\end{array}$ \\
\hline $\begin{array}{l}\text { Mandibular } \\
\text { I1 } \\
\text { I2 } \\
\text { MI } \\
\text { Summed }\end{array}$ & $\begin{array}{r}110-378 \\
170-378 \\
75-378 \\
75-378\end{array}$ & $\begin{array}{l}24 \\
22 \\
27 \\
19\end{array}$ & $\begin{array}{l}0.790 \\
0.811 \\
0.831 \\
0.925\end{array}$ & $\begin{array}{l}21 \\
20 \\
27 \\
21\end{array}$ & $\begin{array}{l}0.797 \\
0.843 \\
0.691 \\
0.867\end{array}$ & $\begin{array}{l}21 \\
20 \\
27 \\
21\end{array}$ & $\begin{array}{l}0.701 \\
0.824 \\
0.903 \\
0.933\end{array}$ \\
\hline
\end{tabular}

Correlations involve the stage of development of individual teeth or the summed values ( $2 T$ ) for I1, 12, and M1 where applicable. 